International Journal of Colorectal Disease

THE TREATMENT PARADIGM OF RIGHT-SIDED METASTATIC COLON CANCER: HARBOURING BRAF MUTATION MAKES THE DIFFERENCE

--Manuscript Draft--

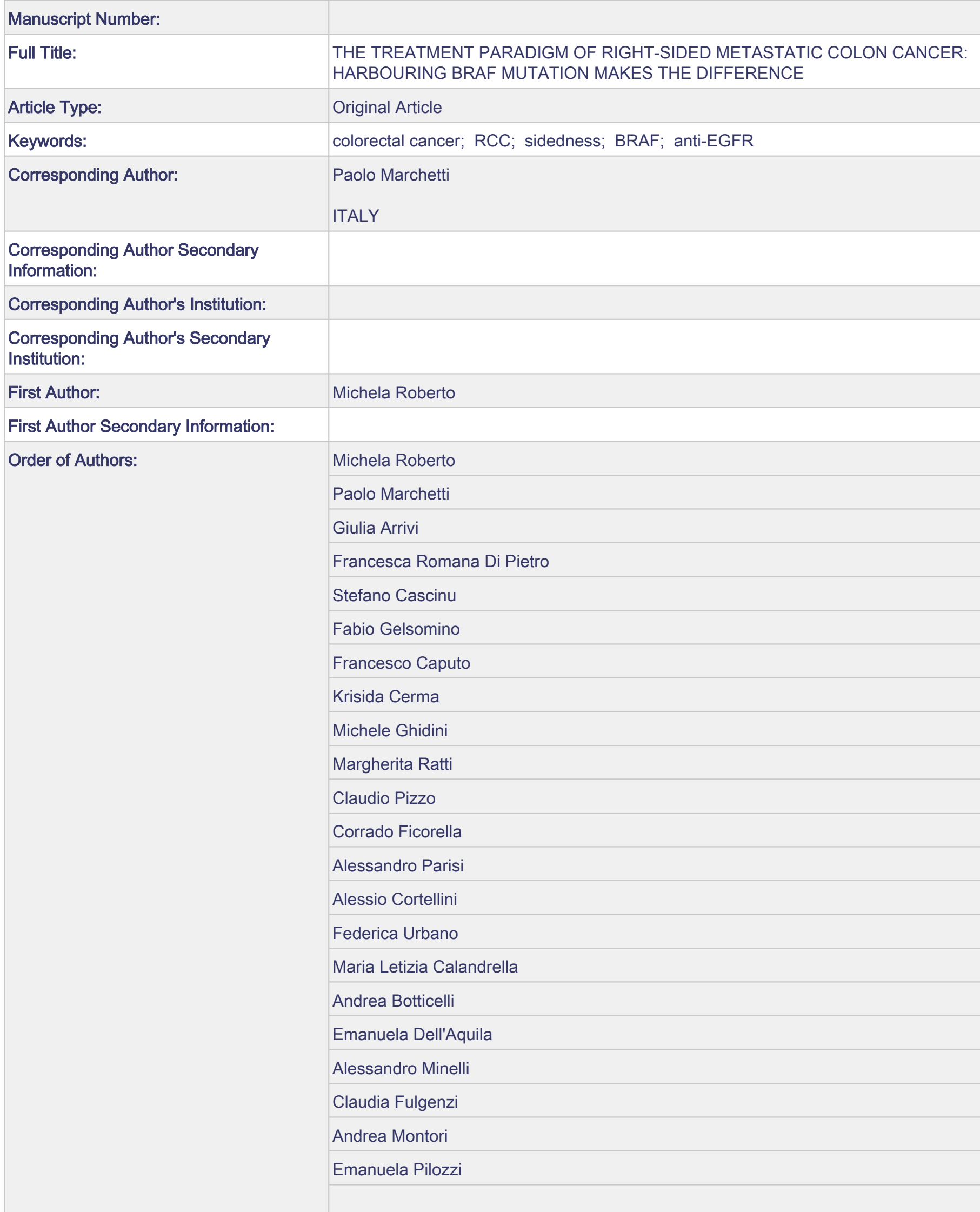




\begin{tabular}{|c|c|}
\hline & Federica Mazzuca \\
\hline \multicolumn{2}{|l|}{ Order of Authors Secondary Information: } \\
\hline \multicolumn{2}{|l|}{ Funding Information: } \\
\hline Abstract: & 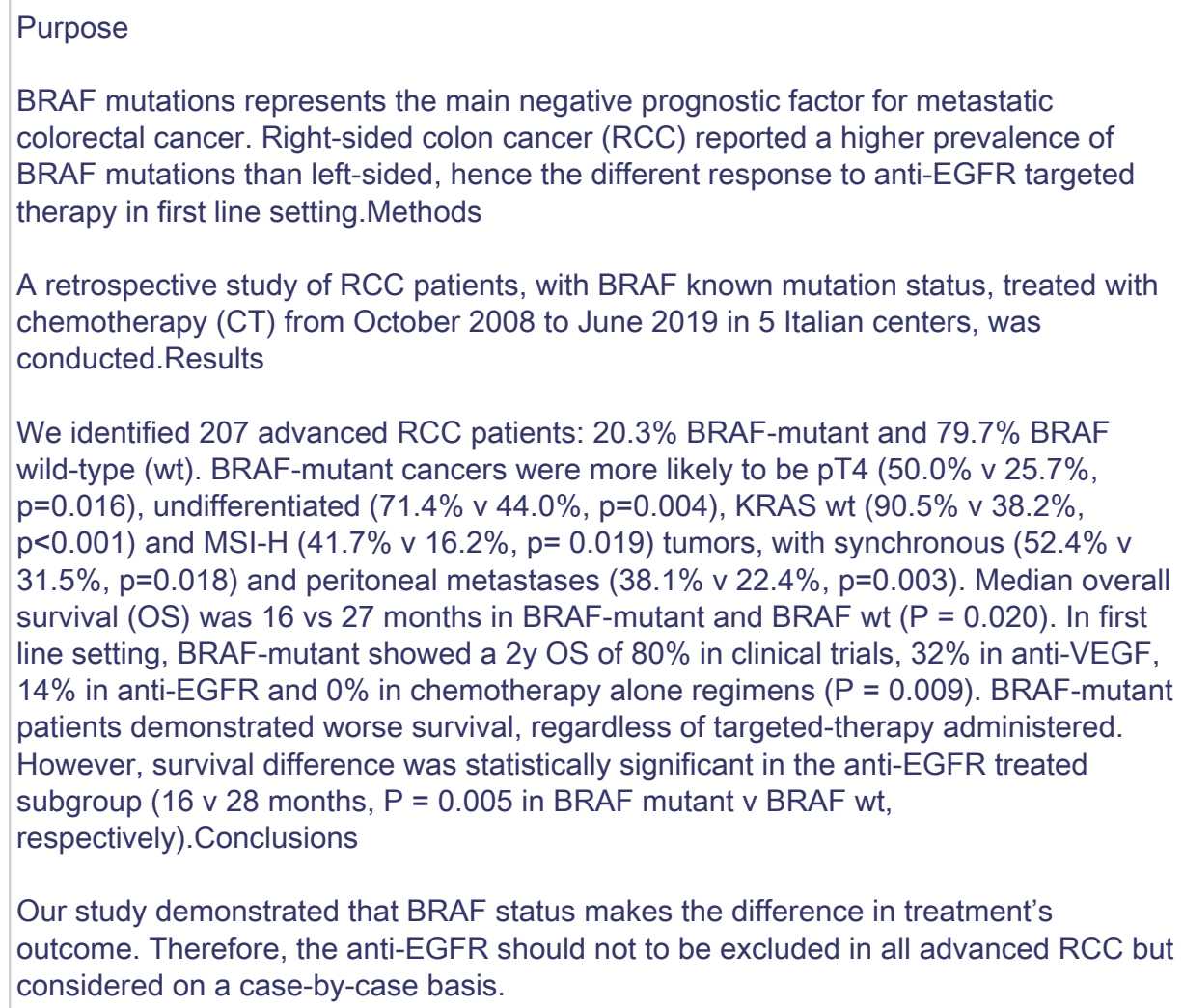 \\
\hline \multicolumn{2}{|l|}{ Additional Information: } \\
\hline Question & Response \\
\hline $\begin{array}{l}\text { 1. Was this manuscript been published } \\
\text { previously or under consideration in whole } \\
\text { or in part somewhere else? }\end{array}$ & no \\
\hline $\begin{array}{l}\text { 2. Was this manuscript in its present form } \\
\text { has been read and approved to } \\
\text { submission to "International Journal of } \\
\text { colorectal disease" for publication by all } \\
\text { participated authors? }\end{array}$ & no \\
\hline 3. Acknowledgments: & none \\
\hline $\begin{array}{l}\text { 4. Conflict of interest or financial } \\
\text { disclosure: }\end{array}$ & none \\
\hline $\begin{array}{l}\text { 5. Do you certify that this research is } \\
\text { entirely original? }\end{array}$ & yes \\
\hline $\begin{array}{l}\text { 6. Which of the following government } \\
\text { agencies provided funding for your } \\
\text { research? }\end{array}$ & none \\
\hline Suggested Reviewers: & $\begin{array}{l}\text { adriana romiti, MD } \\
\text { adromiti@gmail.com } \\
\text { Expert in the field of colon cancer therapy }\end{array}$ \\
\hline
\end{tabular}




\section{THE TREATMENT PARADIGM OF RIGHT-SIDED METASTATIC COLON CANCER: HARBOURING BRAF MUTATION MAKES THE DIFFERENCE}

Michela Roberto ${ }^{1}$, Paolo Marchetti ${ }^{1,5}$, Giulia Arrivi ${ }^{1}$, Francesca Romana Di Pietro ${ }^{1}$, Stefano

Cascinu $^{2}$, Fabio Gelsomino ${ }^{2}$, Francesco Caputo $^{2}$, Krisida Cerma ${ }^{2}$, Michele Ghidini ${ }^{3}$, Margherita Ratti $^{3}$, Claudio Pizzo ${ }^{3}$, Corrado Ficorella ${ }^{4}$, Alessandro Parisi ${ }^{4}$, Alessio Cortellini ${ }^{4}$, Federica Urbano $^{5}$, Maria Letizia Calandrella ${ }^{5}$, Andrea Botticelli ${ }^{1,5}$, Emanuela dell'Aquila ${ }^{6}$, Alessandro Minelli $^{6}$, Claudia Fulgenzi ${ }^{6}$, Andrea Montori ${ }^{7}$, Emanuela Pilozzi ${ }^{7}$, and Federica Mazzuca ${ }^{1}$

1 Department of Clinical and Molecular Medicine, Oncology Unit, Sant' Andrea Hospital, University "La Sapienza," Rome, Italy

2 University Hospital of Modena, Department of Oncology and Hematology, Division of Oncology, Modena, Italy.

3 Oncology Unit, Oncology Department, ASST of Cremona, Cremona, Italy

4 Medical Oncology, St. Salvatore Hospital, University of L'Aquila and Department of Biotechnological and Applied Clinical Sciences, University of L'Aquila, L'Aquila, Italy.

5 Department of Radiology, Oncology and Pathology, Policlinico Umberto I, Sapienza University of Rome, Italy

6 Oncologia Medica, Policlinico Universitario "Campus Bio-Medico di Roma", Rome, Italy 7 Department of Clinical and Molecular Medicine, UOC Anatomia Patologica, Sant' Andrea Hospital, University “La Sapienza,” Rome, Italy

Corresponding author: Paolo Marchetti, Department of Clinical and Molecular Medicine, Sant'Andrea Hospital, University “La Sapienza,” Via di Grottarossa 1035-1039, 00189 Rome, Italy.

Email: paolo.marchetti@uniroma1.it 


\begin{abstract}
Purpose: BRAF mutations represents the main negative prognostic factor for metastatic colorectal cancer. Right-sided colon cancer (RCC) reported a higher prevalence of BRAF mutations than leftsided, hence the different response to anti-EGFR targeted therapy in first line setting. Methods: A retrospective study of RCC patients, with BRAF known mutation status, treated with chemotherapy (CT) from October 2008 to June 2019 in 5 Italian centers, was conducted. Results: We identified 207 advanced RCC patients: 20.3\% BRAF-mutant and 79.7\% BRAF wild-type (wt). BRAF-mutant cancers were more likely to be pT4 $(50.0 \%$ v $25.7 \%, \mathrm{p}=0.016)$, undifferentiated $(71.4 \%$ v $44.0 \%$, $\mathrm{p}=0.004)$, KRAS wt $(90.5 \%$ v 38.2\%, p<0.001) and MSI-H (41.7\% v 16.2\%, p=0.019) tumors, with synchronous $(52.4 \%$ v $31.5 \%, \mathrm{p}=0.018)$ and peritoneal metastases $(38.1 \%$ v $22.4 \%, \mathrm{p}=0.003)$. Median overall survival (OS) was 16 vs 27 months in BRAF-mutant and BRAF wt (P=0.020). In first line setting, BRAF-mutant showed a $2 \mathrm{y}$ OS of $80 \%$ in clinical trials, $32 \%$ in anti-VEGF, $14 \%$ in anti-EGFR and $0 \%$ in chemotherapy alone regimens $(\mathrm{P}=0.009)$. BRAF-mutant patients demonstrated worse survival, regardless of targeted-therapy administered. However, survival difference was statistically significant in the anti-EGFR treated subgroup ( $16 \mathrm{v} 28$ months, $\mathrm{P}=$ 0.005 in BRAF mutant v BRAF wt, respectively). Conclusions: Our study demonstrated that BRAF status makes the difference in treatment's outcome. Therefore, the anti-EGFR should not to be excluded in all advanced RCC but considered on a case-by-case basis.
\end{abstract}

Keywords: colorectal cancer, RCC, sidedness, BRAF, anti-EGFR 


\section{INTRODUCTION}

Colorectal cancer (CRC) is the third most common cancer worldwide [1]. In recent years, the sidedness seems to be a well-established and relevant prognostic factor due to distinct differences in epidemiology, pathogenesis, genetic and epigenetic alterations, molecular pathways and outcome between right and left-side colorectal cancer [2,3]. Anatomically, the right-sided colon cancer (RCC), including cecum, ascending, hepatic flexure and two-third proximal transverse, arises from the midgut and receives its main blood supply via the superior mesenteric artery, whereas the distal colon arises from the hindgut and is supplied by the inferior mesenteric artery.

Moreover, RCC is prevalent among old age patients with iron deficiency anemia at diagnosis [4] and in female gender [5] and is more likely to be diploid and to be characterized by high microsatellite instability [6], CpG island methylation, and BRAF mutations [7-10].

Patients affected with RCC reported an increased frequency of vascular invasion, mucinous type, high grade, invasive tumor border and a higher total number of harvested lymph nodes [11] but with lower rates of node positivity [12] than the left-side colon cancer (LCC) [13].

Furthermore, different signaling pathways are involved in the development of colon cancer: in the RCC is more prevalent the serrated pathway [14,15], in which BRAF mutations develop and CpG island hypermethylation occurs, resulting in gene transcriptional inactivation and loss of gene function by methylation of the promoter region. Otherwise, the conventional pathway with mutations in KRAS, TP53, and APC is associated with LCC.

From this literature data it is clear how the RCC constitutes a different entity than the LCC. All these factors may contribute to the difference observed in patient prognosis and to explain the relationship between cancer location and mortality. Several population-based studies have explored the prognostic relevance of laterality in CRC, with conflicting results [16-20].

Meguid et al[16] reported that right-sided cancers had a higher risk of mortality than left-sided colorectal cancers across all stages (HR, 1.04; 95\% CI, 1.02 to 1.07); It was also confirmed by a more recent meta-analysis [2] of 66 studies published from 1995 to 2016, showed that LCC were associated with improved survival rather than RCC (HR, 0.82; 95\% CI, 0.79-0.84). The association between RCC and higher mortality is strongest for patients with stage III and IV disease [19]. Moreover, the right-sidedness seems to be also a predictive factor of response to first line treatment in mCRC patients. A retrospective analysis from CRYSTAL and FIRE-3 trials, in patients with 
RAS wild-type (wt) mCRC treated with chemotherapy and anti-EGFR targeted agent, found a better response in LCC than RCC patients [21]. On the basis of these results, NCCN guidelines recommend choosing anti-EGFR plus chemo as first line chemotherapy only in left-sided mCRC [22].

Moreover, as shown by the data of CALGB/SWOG 80405 trial, among patients with KRAS wt disease, overall survival (OS) and progression free survival (PFS) were better in those with leftsided primary tumors while, both OS and PFS were better with bevacizumab than with cetuximab in patients with right-sided primary tumors [23]. However, the NRAS and/or BRAF status was not considered.

In general, BRAF mutations are present in about $10 \%$ of colorectal cancer cases but over two-thirds of BRAFV600E tumors originate in the RCC vs the LCC (68 vs 32\%) [7]. The RCC negative prognosis seems to be related with the more frequent BRAF mutations $[24,25]$ which represents the main negative prognostic factor for mCRC, regardless of sidedness and other molecular factors [26]. Indeed, BRAF-mutant CRC has emerged as a distinct biologic entity, refractory to standard chemotherapy regimens approved for the treatment of metastatic CRC and associated with a dismal prognosis [27-29]. An effective therapy has not yet been identified although some positive data have emerged regarding the use of more intensive chemotherapy backbone plus bevacizumab as initial therapy [30] and the more recent multi-targeted therapy combinations [31-34]. Up to date, it is still not clear which is the best therapeutic strategy in RCC tumors, albeit with BRAF mutation. However, clinical trials with combining MAPK pathway targeted therapies are under investigation and could be the best therapeutic strategy [27].

This is a retrospective analysis of metastatic RCC patients referred to 5 Italian centers with the aim to evaluate the outcome of RCC patients according to BRAF status and the treatment performed.

\section{METHODS}

\section{Patients}

A multi-institutional retrospective analysis of clinical data from 207 patients with right mCRC treated with chemotherapy from October 2008 to June 2019 was done. All patients with BRAF known mutation status were included in this analysis. The study was conducted in accordance with the Declaration of Helsinki and Institutional Review Board approval.

\section{Statistical Analysis}


SPSS statistical software, Version 24 (SPSS Inc. Chicago, Illinois, USA) was used. The $\chi^{2}$-test and t-test for unpaired data were applied to compare frequencies and means, respectively. The interaction among clinicopathologic parameters was first analysed using univariate logistic regression. Survival curves were estimated using the Kaplan-Meier method and the log-rank test was used for the difference assessment. A multivariate Cox-proportional hazard model was used to identify independent prognostic factors for survival. All reported $\mathrm{P}$ values are two sided and $\mathrm{P}$ values less than 0.05 are considered statistically significant.

\section{RESULTS}

Clinicopathological Characteristics

This study included 207 right-sided metastatic colon cancer patients with known BRAF mutation status. All patients' clinicopathological characteristics are summarized in Table 1. In total 42 (20.3\%) patients had BRAF mutant tumors and 165 (79.7\%) had BRAF wt tumors. Also KRAS/NRAS and MSI status were considered for the analysis. According to RAS-status, 40 (20\%) patients undergone a first line chemotherapy with an anti-EGFR target agent.

Differences in clinicopathological characteristics between BRAF mutant and BRAF wt tumors are reported in Table 2. BRAF-mutant RCC was significantly more likely to occur in pT4 $(50.0 \% \mathrm{v}$ $25.7 \%, \mathrm{p}=0.016)$, undifferentiated $(71.4 \%$ v $44.0 \%, \mathrm{p}=0.004)$ KRAS wt $(90.5 \%$ v $38.2 \%, \mathrm{p}<0.001)$, MSI-H (41.7\% v 16.2\%, $\mathrm{p}=0.019)$ tumors, with synchronous $(52.4 \%$ v 31.5\%, $\mathrm{p}=0.018)$ and peritoneal metastases ( $38.1 \% \mathrm{v} 22.4 \%, \mathrm{p}=0.003$ ). A higher proportion of BRAF mutant tumors was observed in female patients, although this was not statistically significant (52.4\% v $47.6 \%$ in female and male group, respectively). Moreover, the tumor onset with anemia was more common in BRAF mutant than BRAF wt tumors $(40 \%$ v $27.3 \%, \mathrm{p}=0.065)$ No difference between BRAF status was found in right colon tumor location as well as mucinous histology or lymph-nodes involvement.

\section{Survival analysis}

In our study, BRAF mutant RCC showed a poorer prognosis than BRAF wt tumors with a median OS of 16.0 (range 13.72 -18.27) vs 27.0 (range 21.82 - 31.17) months, respectively (hazard ratio [HR], 1.60; 95\% CI, 1.06-2.41; P = 0.020) (Figure 1a)

Other clinicopathological factors significantly associated with poorer survival included age $>70$ years $(\mathrm{P}=0.002)$, pT4 $(\mathrm{P}=0.009)$, pN2 ( $=0.034), \mathrm{G} 3-4$ tumor grading $(\mathrm{P}=0.009)$ and lympho- 
vascular invasion $(\mathrm{P}=0.013)$ at the histological exam. Moreover, peritoneum as metastatic site $(\mathrm{P}=0.040)$ and the synchronous occurrence of metastases $(\mathrm{P}=0.045)$ were associated with a worse survival. On the contrary, a good ECOG PS $(\mathrm{P}=<0.0001)$, primary resected tumors $(\mathrm{P}=<0.0001)$ and the upfront surgery of liver metastases $(\mathrm{P}=0.001)$ were associated with better outcome. At the multivariate analysis, only BRAF status, baseline ECOG PS and the upfront surgery of metastatic disease were independent prognostic factors of survival (Table 3)

Overall, there was non-significant difference in median OS between first line treatment with mono or doublet chemotherapy (18.0 months, range $10.5-25.4)$, triplet chemo regimen (25.0 months, range 18.1 - 31.8), chemo plus an anti-VEGF (24.0 months, range 13- 24.9) or anti-EGFR (26.0 months, range 20.9 - 31.1) targeted agent and clinical trials with immunotherapy (not reached) (HR $=0.90,95 \%$ CI 0.81-1.00, $\mathrm{P}=0.072$ ). (Figure 2a) However, taking into account the first line regimen, patients enrolled in clinical trials showed a better median progression free survival (PFS1) than others (17.0 v 6.0 v.13.0 months, in clinical trials, CT plus a target agent and triplet CT group, respectively) ( $\mathrm{HR}=0.90,95 \% \mathrm{CI} 0.82-0.99, \mathrm{P}=0.037)$. (Figure $2 \mathrm{~b})$ Beyond first-line treatment, clinical trials and reintroduction of triplet CT regimen performed significantly better than the other treatment strategies (median PFS2 was $16.0 \mathrm{v} 15.0 \mathrm{v} 7.0 \mathrm{v} 5.0 \mathrm{v} 4.0 \mathrm{v} 2.0$ months in clinical trials, triplet CT, CT plus anti-EGFR, CT plus anti-VEGF, CT alone and regorafenib/lonsurf as second line therapy, respectively) $(\mathrm{HR}=0.69,95 \% \mathrm{CI} 0-57-0.85, \mathrm{P}=0.001)$ (Figure 2c). Although a more intensified chemotherapy regimen seems to give more survival benefit, non-significant difference was found among third-line treatments (HR for PFS3 $=1.0,95 \%$ CI 0.94-1.07, $\mathrm{P}=0.883$ ) (Figure 2d)

In a bivariate analysis where BRAF status was stratified by treatments, there was no significant survival differences between first line CT with anti-EGFR or anti-VEGF targets in BRAF wt tumors (Figure 1b), while, in BRAF mutant tumors, 2 ys OS was $80 \%$ v $32 \%$ v $14 \%$ v $0 \%$ in clinical trials, anti-VEGF, anti-EGFR and CT alone regimen, respectively $(\mathrm{HR}=0.63,95 \% \mathrm{CI}$ 0.45-0.89, $\mathrm{P}$ $=0.009$ ) (Figure 1c). In the reverse analysis where anti-EGFR and anti-VEGF based chemotherapy were stratified by BRAF status, we demonstrated poorer survival for BRAF mutant tumors regardless of targeted-therapy administered even if there was a significantly difference only in the subgroup of patients treated with CT plus anti-EGFR target agents, where BRAF mutant showed a significant lower OS. (HR for anti-EGFR $=16 \mathrm{v} 28$ months in BRAF mutant v BRAF wt tumors, $\mathrm{P}$ $=0.005 ;$ HR for anti-VEGF $=18 \mathrm{v} 26$ months in BRAF mutant $\mathrm{v}$ BRAF wt tumors, $\mathrm{P}=0.509$ ). (Figure 3a. 3b)

\section{DISCUSSION}


By now we know that RCC is a completely different entity with a different embryological origin, molecular pathways (harboring BRAF, PIK3CA, and KRAS mutations, more frequently with MSI$\mathrm{H}$ phenotye) and poorer outcome than LCC [2-15]. Therefore, a better understanding of RCC behavior is crucial to explain the different response to chemotherapy and the available targeted agents.

The worse prognosis of RCC is confirmed irrespective of the therapeutic strategy [26, 35, 36] although a triplet chemotherapy backbone plus bevacizumab as initial therapy [30] and especially a multi-targeted therapy combination seems to be the best future therapeutic choice [31-34].

We conducted a multi-institutional retrospective analysis of advanced RCC patients with known BRAF status and available treatment data with the aim to identify predictive factors for survival and the difference between target agents compound in first line chemotherapy choice.

The proportion of BRAF mutant tumors (42/207 patients) was consistent across this population and more large-scale cohorts' study (57/201 patients), including RCC [7]. According to the recently published largest series of V600E BRAF-mutated mCRC [37], our study confirmed a median overall survival in BRAF mutant tumors of less than 20 months and significantly worse OS in patients with an ECOG PS $>1(\mathrm{P}=<0.0001)$, G3-4 tumor grading $(\mathrm{P}=0.009)$, with lymphovascular invasion $(\mathrm{P}=0.013)$, not having the primary tumor resected $(\mathrm{P}=<0.0001)$.

Moreover, according to the largest stage IV colon cancer analysis for survival [17], our study showed older age $(\mathrm{P}=0.002)$, pT4 $(\mathrm{P}=0.009), \mathrm{pN} 2(\mathrm{P}=0.034)$, peritoneum as metastatic site (0.040), and the synchronous occurrence of metastases $(\mathrm{P}=0.045)$, independent of the number of metastatic site, as significantly negative prognostic factor of survival. On the contrary, the upfront surgery of liver metastases $(\mathrm{P}=0.001)$ was associated with better outcome.

As previously described [37], BRAF mutant RCC tumors was significantly reported in pT4 (P = 0.016), G3-4 tumor grading ( $\mathrm{P}=0.004)$ KRAS-wt $(\mathrm{P}<0.0001)$, MSI-H $(\mathrm{P}=0.019)$, metachronous $(\mathrm{P}=0.018)$, especially peritoneal metastases $(\mathrm{P}=0.003)$.

Several trials on metastatic setting have found worsen outcomes in RCC patients rather than LCC, and a different therapeutic response to the anti-EGFR targetd agents [38]. Effectively, a chemotherapy doublet or triplet plus bevacizumab was indirectly approved by retrospective, posthoc analysis mainly focused on describing differences between RCC and LCC [39-42], as the new standard first line chemotherapy for metastatic RCC, regardless of RAS status. 
Non-significant difference was found between treatment arms, irrespective of anti-VEGF or anti-

EGFR target agent first line therapy used, although patients enrolled in clinical trials showed a better median PFS1 than CT plus target agent as well as triplet CT group (17.0 v 6.0 v.13.0 months, respectively).

RCC patients are characterized by a MSI-high cancer more frequently than LCC [6], and by a higher total number of harvested lymph nodes [11] but with lower rates of node positivity [12]. The reasons for these node-status differences were both anatomic and molecular: it has been shown as the right-sided colon mesentery contains a more complex lymphatic system, leading to an enhanced immune response and an increased number of lymph nodes examined after surgey [43,44].In this retrospective analysis, a small number of patients with MSI-H phenotype were enrolled in clinical trials with an anti-PD1 and actually reported a significant better outcome than patients who were not enrolled in clinical trials. (HR for PFS1 $=0.90,95 \%$ CI 0.82-0.99, P = 0.037; HR for PFS2 = $0.69,95 \%$ CI 0-57-0.85, $\mathrm{P}=0.001$ ).

With regard to the second-line CT, we did not find any differences between anti-VEGF or antiEGFR target agents, with the exception of significant better survival in clinical trials and in which cases of patients resulted to be fit for reintroduction of triplet CT regimen (median PFS2 was $16.0 \mathrm{v}$ 15.0 7.0 v 5.0 v 4.0 2.0 months in clinical trials, triplet CT, CT plus anti-EGFR, CT plus antiVEGF, CT alone and regorafenib/lonsurf as second line therapy, respectively) $(\mathrm{HR}=0.69,95 \% \mathrm{CI}$ $0-57-0.85, \mathrm{P}=0.001$ )

Actually, BRAF mutant RCC patients in this study reported a median OS of 16 months (range 13.7 -18.3) which was not so far from median OS reported in BRAF-mutant patients enrolled in the TRIBE trial [30], with a worse survival than BRAF wt patients, both in anti-VEGF and anti-EGFR target agent treatment groups. In the bivariate analysis, where BRAF status was stratified by treatments, there was showed non-significant survival differences between first line CT with antiEGFR or anti-VEGF targets in both BRAF and RAS wt tumors (28.0 v 26.0 months, respectively. P $=0.427$ ) (Figure 1b). But if we looked at only BRAF mutant tumors, 2ys OS was significantly higher in clinical trials group ( $80 \%$ v $32 \%$ v $14 \%$ v $0 \%$ in clinical trials, anti-VEGF, anti-EGFR plus $\mathrm{CT}$, and $\mathrm{CT}$ alone or triplet backbone regimen, respectively; $\mathrm{HR}=0.63,95 \% \mathrm{CI} 0.45-0.89, \mathrm{P}=$ 0.009) (Figure 1c). At the reverse analysis where anti-EGFR and anti-VEGF based chemotherapy were stratified by BRAF status, we demonstrated that BRAF mutant tumors reported a poorer survival than BRAF wt tumors, regardless of targeted-therapy administered. However, RAS wt tumors treated with CT plus anti-EGFR showed a significant difference in survival according to BRAF mutation (HR for anti-EGFR $=16 \mathrm{v} 28$ months in BRAF mutant $\mathrm{v}$ BRAF wt tumors, $\mathrm{P}=$ 
0.005; HR for anti-VEGF $=18 \mathrm{v} 26$ months in BRAF mutant $\mathrm{v}$ BRAF wt tumors, $\mathrm{P}=0.509$ ). (Figure 3a. 3b). These data, taking into account the prevalence of BRAF mutation in RCC, may explain the more pronounced lower effect in RCC than LCC, reported in post-hoc analysis of clinical trials focused on anti-EGFR therapy in the first-line setting [45]. Furthermore, RCC was associated with Consensus Molecular Subtypes (CMS) different from LCC [46-48] and these molecular patterns may also explain the different response to targeted agents. Indeed, a retrospective analysis of the CALGB/SWOG 80405 which compared the efficacy of Cetuximab v Bevacizumab when added to standard first line chemotherapy, found that RAS wt patients with CMS1 (mostly RCC patients) benefitted significantly more if they had been randomized to Bevacizumab compared to Cetuximab, whereas a trend towards better outcomes was observed for CMS2 patients if they had been randomized to Cetuximab. Based on these observations and given the real-life results of our analysis, further studies are needed to determine if these molecular signatures according to sidedness are crucial predictive markers of response to specific targeted agents, and also to definitively answer the question about the best first line chemotherapy in RASwt, BRAF-mutant, RCC patients.

\section{CONCLUSIONS}

Advanced RCC is a different entity from LCC, with a significant correlation with known negative prognostic factors such as advanced $\mathrm{pT}$ and $\mathrm{pN}$ stage, dedifferentiated tumor grading, metachronous and peritoneal metastases. All these clinicopathological factors may contribute to the difference observed in patient's prognosis with increasing pooled data demonstrating a shorter survival for patients with RCC than LCC tumors. Although the limit of sample size, our study demonstrated that BRAF status makes the difference for treatment response. Therefore, a first-line CT plus an antiEGFR targeted agent should not to be excluded in all RCC cases in advance but considered on a case-by-case basis. Meanwhile, RCC patient with BRAF mutant tumors or with MSI-H phenotype, who do not respond to standard treatment, should be more much deemed to be enrolled in clinical trials. Certainly, a better knowledge of the main specific predictive factors in selected subgroups of RCC patients and prospective clinical trials stratifying participants according to primary tumor location would be very useful for helping physician in the future therapeutic algorithm choice.

Conflict of interest: The authors declare that they have no conflict of interest 


\section{REFERENCES}

1. Stewart BW, Wild CP. World cancer report 2014. World Heal Organ. 2014. doi:9283204298

2. Petrelli F, Tomasello G, Borgonovo K, et al. Prognostic survival associated with left-sided vs right-sided colon cancer a systematic review and meta-analysis. JAMA Oncol. 2017. doi:10.1001/jamaoncol.2016.4227

3. Karim S, Brennan K, Nanji S, Berry SR, Booth CM. Association between prognosis and tumor laterality in early-stage colon cancer. JAMA Oncol. 2017. doi:10.1001/jamaoncol.2017.1016

4. Beale AL, Penney MD, Allison MC. The prevalence of iron deficiency among patients presenting with colorectal cancer. Color Dis. 2005. doi:10.1111/j.1463-1318.2005.00789.x

5. Cheng L, Eng C, Nieman LZ, Kapadia AS, Du XL. Trends in colorectal cancer incidence by anatomic site and disease stage in the United States from 1976 to 2005. Am J Clin Oncol Cancer Clin Trials. 2011. doi:10.1097/COC.0b013e3181fe41ed

6. Markowitz SD, Bertagnolli MM. Molecular origins of cancer: Molecular basis of colorectal cancer. N Engl J Med. 2009. doi:10.1056/NEJMra0804588

7. Tran B, Kopetz S, Tie J, et al. Impact of BRAF mutation and microsatellite instability on the pattern of metastatic spread and prognosis in metastatic colorectal cancer. Cancer. 2011. doi:10.1002/cncr.26086

8. Bufill JA. Colorectal cancer: Evidence for distinct genetic categories based on proximal or distal tumor location. Ann Intern Med. 1990. doi:10.7326/0003-4819-113-10-779

9. Iacopetta B. Are there two sides to colorectal cancer? Int J Cancer. 2002. doi:10.1002/ijc.10635

10. Distler P, Holt PR. Are right- and left-sided colon neoplasms distinct tumors? Dig Dis. 1997. doi:10.1159/000171605

11. Mik M, Berut M, Dziki L, Trzcinski R, Dziki A. Right-and left-sided colon cancer-clinical and pathological differences of the disease entity in one organ. Arch Med Sci. 2017. doi:10.5114/aoms.2016.58596

12. Guan X, Chen W, Liu Z, et al. Whether regional lymph nodes evaluation should be equally required for both right and left colon cancer. Oncotarget. 2016. doi:10.18632/oncotarget.11007 
13. Gowarty JL, Durham C, Wong L, Chen W. Survival outcomes of left-sided versus rightsided colon cancer. J Clin Oncol. 2019. doi:10.1200/jco.2019.37.4_suppl.502

14. Nosho K, Irahara N, Shima K, et al. Comprehensive biostatistical analysis of CpG island methylator phenotype in colorectal cancer using a large population-based sample. PLoS One. 2008. doi:10.1371/journal.pone.0003698

15. W.S. S, H. A, J. H, et al. Evaluation of a large, population-based sample supports a CpG island methylator phenotype in colon cancer. Gastroenterology. 2005.

16. Meguid RA, Slidell MB, Wolfgang CL, Chang DC, Ahuja N. Is there a difference in survival between right- versus left-sided colon cancers? Ann Surg Oncol. 2008. doi:10.1245/s10434008-0015-y

17. Weiss JM, Pfau PR, O’Connor ES, et al. Mortality by stage for right- versus left-sided colon cancer: Analysis of surveillance, epidemiology, and end results-medicare data. J Clin Oncol. 2011. doi:10.1200/JCO.2011.36.4414

18. Warschkow R, Sulz MC, Marti L, et al. Better survival in right-sided versus left-sided stage I - III colon cancer patients. BMC Cancer. 2016. doi:10.1186/s12885-016-2412-0

19. Schrag D, Weng S, Brooks G, Meyerhardt JA, Venook AP. The relationship between primary tumor sidedness and prognosis in colorectal cancer. J Clin Oncol. 2016. doi:10.1200/jco.2016.34.15_suppl.3505

20. Kennecke HF, Speers C, Davies JM, Cheung WY, Lee-Ying RM. Differences in relapse-free survival (RFS) and survival after relapse (SAR) in right (R) versus left (L) stage I-III colon cancer (CCa). J Clin Oncol. 2016. doi:10.1200/jco.2016.34.15_suppl.3578

21. Tejpar S, Stintzing S, Ciardiello F, Tabernero J, Van Cutsem E, Beier F, Esser R, Lenz HJ, Heinemann V. Prognostic and Predictive Relevance of Primary Tumor Location in Patients With RAS Wild-Type Metastatic Colorectal Cancer: Retrospective Analyses of the CRYSTAL and FIRE-3 Trials. JAMA Oncol. 2017 Feb 1;3(2):194-201. doi: 10.1001/jamaoncol.2016.3797.

22. Benson AB, Venook AP, Al-Hawary MM, et al. NCCN Guidelines Insights: Colon Cancer, Version 2.2018. J Natl Compr Cancer Netw. 2018. doi:10.6004/jnccn.2018.0021

23. Venook AP, Niedzwiecki D, Innocenti F, et al. Impact of primary $\left(1^{\circ}\right)$ tumor location on overall survival (OS) and progression-free survival (PFS) in patients (pts) with metastatic 
colorectal cancer (mCRC): Analysis of CALGB/SWOG 80405 (Alliance). J Clin Oncol. 2016. doi:10.1200/jco.2016.34.15_suppl.3504

24. Lee GH, Malietzis G, Askari A, Bernardo D, Al-Hassi HO, Clark SK. Is right-sided colon cancer different to left-sided colorectal cancer? - A systematic review. Eur J Surg Oncol. 2015. doi:10.1016/j.ejso.2014.11.001

25. Benedix F, Schmidt U, Mroczkowski P, Gastinger I, Lippert H, Kube R. Colon carcinoma Classification into right and left sided cancer or according to colonic subsite? - Analysis of 29568 patients. Eur J Surg Oncol. 2011. doi:10.1016/j.ejso.2010.12.004

26. Loupakis F, Yang D, Yau L, et al. Primary tumor location as a prognostic factor in metastatic colorectal cancer. J Natl Cancer Inst. 2015. doi:10.1093/jnci/dju427

27. Lee HM, Morris V, Napolitano S, Kopetz S. Evolving strategies for the management of BRAF-mutant metastatic colorectal cancer. Oncol (United States). 2019.

28. Taieb J, Lapeyre-Prost A, Laurent Puig P, Zaanan A. Exploring the best treatment options for BRAF-mutant metastatic colon cancer. Br J Cancer. 2019. doi:10.1038/s41416-019-0526-2

29. Morris V, Overman MJ, Jiang ZQ, et al. Progression-free survival remains poor over sequential lines of systemic therapy in patients with BRAF-mutated colorectal cancer. Clin Colorectal Cancer. 2014. doi:10.1016/j.clcc.2014.06.001

30. Cremolini C, Loupakis F, Antoniotti C, et al. FOLFOXIRI plus bevacizumab versus FOLFIRI plus bevacizumab as first-line treatment of patients with metastatic colorectal cancer: Updated overall survival and molecular subgroup analyses of the open-label, phase 3 TRIBE study. Lancet Oncol. 2015. doi:10.1016/S1470-2045(15)00122-9

31. Ledys F, Derangère V, Réda $M$, et al. Anti-MEK and Anti-EGFR mAbs in RAS-Mutant Metastatic Colorectal Cancer: Case Series and Rationale. Adv Ther. 2019. doi:10.1007/s 12325-019-00949-y

32. Bendell JC, Atreya CE, André T, et al. Efficacy and tolerability in an open-label phase I/II study of MEK inhibitor trametinib (T), BRAF inhibitor dabrafenib (D), and anti-EGFR antibody panitumumab (P) in combination in patients (pts) with BRAF V600E mutated colorectal cancer (CRC). J Clin Oncol. 2014. doi:10.1200/jco.2014.32.15_suppl.3515

33. Corcoran RB, Atreya CE, Falchook GS, et al. Combined BRAF and MEK inhibition with dabrafenib and trametinib in BRAF V600-Mutant colorectal cancer. In: Journal of Clinical 
Oncology. ; 2015. doi:10.1200/JCO.2015.63.2471

34. Kopetz S, Grothey A, Yaeger R, et al. Encorafenib, binimetinib, and cetuximab in BRAF V600E-mutated colorectal cancer. N Engl J Med. 2019. doi:10.1056/NEJMoa1908075

35. Brulé SY, Jonker DJ, Karapetis CS, et al. Location of colon cancer (right-sided versus leftsided) as a prognostic factor and a predictor of benefit from cetuximab in NCIC CO.17. Eur $J$ Cancer. 2015. doi:10.1016/j.ejca.2015.03.015

36. Boeckx N, Janssens K, Van Camp G, et al. The predictive value of primary tumor location in patients with metastatic colorectal cancer: A systematic review. Crit Rev Oncol Hematol. 2018. doi:10.1016/j.critrevonc.2017.11.003

37. Loupakis F, Intini R, Cremolini C, et al. A validated prognostic classifier for V600EBRAFmutated metastatic colorectal cancer: the 'BRAF BeCool' study. Eur J Cancer. 2019. doi:10.1016/j.ejca.2019.06.008

38. Stintzing S, Miller-Phillips L, Modest DP, et al. Impact of BRAF and RAS mutations on first-line efficacy of FOLFIRI plus cetuximab versus FOLFIRI plus bevacizumab: analysis of the FIRE-3 (AIO KRK-0306) study. Eur J Cancer. 2017. doi:10.1016/j.ejca.2017.03.023

39. Modest DP, Ricard I, Heinemann V, et al. Outcome according to KRAS-, NRAS- and BRAF-mutation as well as KRAS mutation variants: Pooled analysis of five randomized trials in metastatic colorectal cancer by the AIO colorectal cancer study group. Ann Oncol. 2016. doi:10.1093/annonc/mdw261

40. Boeckx N, Koukakis R, de Beeck KO, et al. Primary tumor sidedness has an impact on prognosis and treatment outcome in metastatic colorectal cancer: Results from two randomized first-line panitumumab studies. Ann Oncol. 2017. doi:10.1093/annonc/mdx 119

41. Boeckx N, Koukakis R, Op de Beeck K, et al. Effect of Primary Tumor Location on Secondor Later-line Treatment Outcomes in Patients With RAS Wild-type Metastatic Colorectal Cancer and All Treatment Lines in Patients With RAS Mutations in Four Randomized Panitumumab Studies. Clin Colorectal Cancer. 2018. doi:10.1016/j.clcc.2018.03.005

42. Cremolini C, Antoniotti C, Lonardi S, et al. Primary tumor sidedness and benefit from FOLFOXIRI plus bevacizumab as initial therapy for metastatic colorectal cancer.

Retrospective analysis of the TRIBE trial by GONO. Ann Oncol. 2018. doi:10.1093/annonc/mdy140 
43. Bilimoria KY, Palis B, Stewart AK, et al. Impact of tumor location on nodal evaluation for colon cancer. Dis Colon Rectum. 2008. doi:10.1007/s10350-007-9114-2

44. Shen H, Yang J, Huang Q, et al. Different treatment strategies and molecular features between right-sided and left-sided colon cancers. World J Gastroenterol. 2015. doi:10.3748/wjg.v21.i21.6470

45. J Ross P, Srikandarajah K, de Naurois J. Right versus left-sided colon cancer: Is it time to consider these as different diseases? AIMS Med Sci. 2018. doi:10.3934/medsci.2018.3.303

46. Roepman P, Schlicker A, Tabernero J, et al. Colorectal cancer intrinsic subtypes predict chemotherapy benefit, deficient mismatch repair and epithelial-to-mesenchymal transition. Int J Cancer. 2013. doi:10.1002/ijc.28387

47. Perez Villamil B, Romera Lopez A, Hernandez Prieto S, et al. Colon cancer molecular subtypes identified by expression profiling and associated to stroma, mucinous type and different clinical behavior. BMC Cancer. 2012;12(1):260. doi:10.1186/1471-2407-12-260

48. Sadanandam A, Lyssiotis CA, Homicsko K, et al. A colorectal cancer classification system that associates cellular phenotype and responses to therapy. Nat Med. 2013. doi:10.1038/nm.3175

\section{Figure Captions}

Fig. 1a-c Overall survival (OS) according to BRAF status (a). OS in BRAF wild-type tumors (b) and BRAF mutant tumors (c) according to first line chemotherapy performed.

Fig. 2a-d Study population OS according to first line chemotherapy performed (a). Progression free survival according to first line (PFS1) (b), second line (PFS2) (c) and third line (PFS3) therapy (d).

Fig. 3a-b The reverse analysis of OS where anti-EGFR (a) and anti-VEGF (b) based therapies were stratified by BRAF status. 
Table 1. All clinicopathologic features (valid cases and percentages)

\begin{tabular}{lrl}
\hline Total & N. $\%$ \\
Age & $207 \quad 100$ \\
& Median (range) & \\
& $66(38-86)$
\end{tabular}

Age category

$\begin{array}{lrr}\leq 70 & 127 & 61.4 \\ >70 & 80 & 38.6\end{array}$

Sex

$\begin{array}{lll}\text { Male } & 126 & 60.9\end{array}$

$\begin{array}{lrr}\text { Female } & 81 & 39.1\end{array}$

Charlson Comorbidity Index
$\leq 8$
10450.2
$>8$
$96 \quad 46.4$
Not available
$7 \quad 3.4$

Tumor onset
Anemia
$50 \quad 24.2$
Intestinal occlusion
$42 \quad 20.3$
Pain
$13 \quad 6.3$
Intestinal perforation 4
$4 \quad 1.9$
other (fever, weight loss, asthenia)
$54 \quad 26.1$

Primary tumor resected

$\begin{array}{lrr}\text { Yes } & 45 & 21.7 \\ \text { No } & 162 & 78.3\end{array}$

Tumor location

$\begin{array}{lll}\text { Ascending and proximal hepatic flexure } & 90 \quad 43.5\end{array}$

$\begin{array}{lll}\text { Cecum } & 70 & 33.8\end{array}$

$\begin{array}{lll}\text { Distal hepatic flexure and two-third } & 47 & 22.7\end{array}$

proximal transverse

pT
$\leq 3$
$100 \quad 48.3$
4
$45 \quad 21.7$

pN
0
$35 \quad 16.9$
1
$47 \quad 22.7$
2
$67 \quad 32.4$

Lymphovascular/perineural Invasion
Yes
$87 \quad 20.3$
No
$42 \quad 42.0$

Tumor Grading

G1 - 2

$85 \quad 41.1$ 


\begin{tabular}{|c|c|c|}
\hline G3 - 4 & 84 & 40.6 \\
\hline \multicolumn{3}{|l|}{ Mucinous Histology } \\
\hline Yes & 60 & 29.0 \\
\hline No & 140 & 67.6 \\
\hline \multicolumn{3}{|l|}{ KRAS } \\
\hline Wild-type & 101 & 48.8 \\
\hline Mutated & 106 & 51.2 \\
\hline \multicolumn{3}{|l|}{ NRAS } \\
\hline Wild-type & 128 & 61.8 \\
\hline Mutated & 7 & 3.4 \\
\hline \multicolumn{3}{|l|}{ BRAF } \\
\hline Wild-type & 165 & 79.7 \\
\hline Mutated & 42 & 20.3 \\
\hline \multicolumn{3}{|l|}{ Microsatellite Instability } \\
\hline MSS & 66 & 31.9 \\
\hline MSI-High & 19 & 9.2 \\
\hline \multicolumn{3}{|l|}{ Baseline ECOG Performance status } \\
\hline 0 & 149 & 72.0 \\
\hline$\geq 1$ & 58 & 28.0 \\
\hline \multicolumn{3}{|l|}{ Adjuvant chemotherapy } \\
\hline Yes & 51 & 24.6 \\
\hline No & 156 & 75.4 \\
\hline \multicolumn{3}{|l|}{ Adjuvant oxaliplatin } \\
\hline Yes & 43 & 20.7 \\
\hline \multicolumn{3}{|l|}{ Upfront treatment of liver metastases } \\
\hline Surgery & 49 & 23.7 \\
\hline RFA/TACE & 10 & 4.8 \\
\hline \multicolumn{3}{|l|}{ Presentations of metastases } \\
\hline Synchronous & 133 & 64.3 \\
\hline Metachronous & 74 & 35.7 \\
\hline \multicolumn{3}{|l|}{ Site of metastases at diagnosis } \\
\hline Liver & 122 & 58.9 \\
\hline Lung & 22 & 10.6 \\
\hline Peritoneum & 53 & 25.6 \\
\hline Local relapse & 7 & 3.4 \\
\hline Distant nodes & 3 & 1.4 \\
\hline \multicolumn{3}{|l|}{ N. of metastatic sites } \\
\hline 1 & 81 & 39.1 \\
\hline$\geq 2$ & 126 & 60.9 \\
\hline \multicolumn{3}{|l|}{ First line Chemotherapy (CT) regimen } \\
\hline CT alone (mono/doublet regimen) & $38(6 / 32)$ & $18.4(2.9 / 15.5)$ \\
\hline
\end{tabular}




\begin{tabular}{|c|c|c|}
\hline CT plus anti-VEGF & 80 & 39.0 \\
\hline CT plus anti-EGFR & 38 & 18.4 \\
\hline Triplets CT (plus anti-VEGF/anti-EGFR) & $38(13 / 2)$ & $18.4(6.3 / 1.0$ \\
\hline Clinical Trials & $5(5)$ & 2.4 \\
\hline No CT & 7 & 3.4 \\
\hline \multicolumn{3}{|l|}{ Second Line } \\
\hline $\mathrm{CT}$ alone (mono/doublet regimen) & $33(9 / 24)$ & $15.9(7.0 / 18.8$ \\
\hline CT plus anti-VEGF (Bevacizumab/Aflibercept) & $68(46 / 22)$ & $53.2(22.2 / 10.6$ \\
\hline CT plus anti-EGFR & 5 & 2.4 \\
\hline Triplets CT (plus anti-VEGF/anti-EGFR) & $9(2 / 0)$ & $4.3(1.0 / 0$ \\
\hline Clinical trials & 9 & 4.3 \\
\hline Regorafenib & 3 & 1.5 \\
\hline Tas102 & 1 & 0.5 \\
\hline \multicolumn{3}{|l|}{ Third Line } \\
\hline CT alone (mono/doublet CT) & $25(11 / 14)$ & $12.1(5.3 / 6.8$ \\
\hline CT plus anti-VEGF & 7 & 3.4 \\
\hline CT plus anti-EGFR & 2 & 1.0 \\
\hline Triplets CT (plus anti-VEGF/anti-EGFR) & $4(2 / 0)$ & $1.9(1.0 / 0$ \\
\hline Clinical Trials & 3 & 1.5 \\
\hline Regorafenib & 17 & 8.2 \\
\hline Tas 102 & 5 & 2.4 \\
\hline \multicolumn{3}{|l|}{ Beyond 3-line Treatment } \\
\hline Yes/Rechallange & $35 / 19$ & $16.9 / 9.2$ \\
\hline
\end{tabular}

Abbreviations : RFA: radiofrequency ablation, TACE: transarterial chemoembolization 
Table 2. Clinicopathologic parameters distribution between BRAF-wild type (wt) and BRAF-mutant tumors

\begin{tabular}{rlll}
\hline & BRAF-wt & BRAF-mutant & P \\
Total & $\mathrm{N}(\%)$ & $\mathrm{N}(\%)$ & \\
Age category & & & \\
$\leq 70$ & $102(61.8)$ & $25(59.5)$ & 0.860 \\
$>70$ & $63(38.2)$ & $17(40.5)$ &
\end{tabular}

Sex

$\begin{array}{llll}\text { Male } & 105(63.6) & 20(47.6) & \\ \text { Female } & 60(36.4) & 22(52.4) & 0.077\end{array}$

Charlson Comorbidity Index

$\begin{array}{llcl}\leq 8 & 80(49.7) & 24(61.5) & \\ >8 & 81(50.3) & 15(38.5) & 0.213\end{array}$

Tumor onset

$\begin{array}{llll}\text { Anemia } & 35(27.3) & 14(40.0) & \\ \text { Intestinal occlusion } & 33(25.8) & 9(25.7) & 0.171 \\ \text { Pain } & 14(10 .) & 0(0.0) & 0(0.0) \\ \text { Intestinal perforation } & 4(3.1) & 12(34.3)\end{array}$

Primary tumor resected
Yes
$129(78.2)$
33 (78.6)
No
$36(21.8)$
9 (21.4)
1.000

Tumor location

$\begin{array}{llll}\text { Ascending and proximal hepatic flexure } & 69(41.8) & 21(50.0) & \\ \text { Cecum } & 60(36.4) & 10(23.8) & 0.308 \\ \text { Distal hepatic flexure and two-third } & 36(21.8) & 11(26.2) \\ \text { proximal transverse } & & \end{array}$

pT
$\leq 3$
84 (74.3)
16 (50.0)
4
$29(25.7)$
$16(50.0)$
0.016

pN

$\begin{array}{llll}0 & 28(24.1) & 7(21.2) & \\ 1 & 39(33.6) & 8(24.2) & 0.433 \\ 2 & 49(42.2) & 18(54.5) & \end{array}$

Lymphovascular/perineural Invasion
Yes
$64(65.3)$
$23(74.2)$
No
34 (34.7)
$8(25.8)$
0.389

Tumor Grading
G1 - 2
75 (56.0)
$10(28.6)$
G3 - 4
$59(44.0)$
25 (71.4)
0.004

Mucinous Histology 


\begin{tabular}{|c|c|c|c|}
\hline No & $115(72.8)$ & 26 (61.9) & \\
\hline \multicolumn{4}{|l|}{ KRAS } \\
\hline Wt & $63(38.2)$ & $38(90.5)$ & \\
\hline mut & $102(61.8)$ & $4(9.5)$ & $<0.0001$ \\
\hline \multicolumn{4}{|l|}{ NRAS } \\
\hline Wt & $90(93.8)$ & 38 (97.4) & 0.673 \\
\hline Mut & $6(6.3)$ & $1(2.6)$ & \\
\hline \multicolumn{4}{|l|}{ Microsatellite Instability } \\
\hline MSS & $57(83.8)$ & 9 (52.9) & \\
\hline MSI-H & $11(16.2)$ & $8(47.1)$ & 0.019 \\
\hline \multicolumn{4}{|c|}{ Baseline ECOG Performance status } \\
\hline 0 & 117 (70.9) & $32(76.2)$ & \\
\hline$\geq 1$ & $48(29.1)$ & $10(23.8)$ & 0.567 \\
\hline \multicolumn{4}{|c|}{ Presentations of metastases } \\
\hline Synchronous & $113(68.5)$ & $20(47.6)$ & \\
\hline Metachronous & $52(31.5)$ & $22(52.4)$ & 0.018 \\
\hline \multicolumn{4}{|c|}{ Site of metastases at diagnosis } \\
\hline Liver & $101(61.2)$ & $21(50.0)$ & \\
\hline Lung & $22(13.3)$ & $0(0.0)$ & \\
\hline Peritoneum & $37(22.4)$ & $16(38.1)$ & 0.003 \\
\hline Local relapse & $4(2.4)$ & $3(7.1)$ & \\
\hline Distant nodes & $1(0.6)$ & $2(4.8)$ & \\
\hline \multicolumn{4}{|l|}{ N. of metastatic sites } \\
\hline 1 & $60(36.4)$ & $21(50.0)$ & \\
\hline$\geq 2$ & $105(63.6)$ & $21(50.0)$ & 0.114 \\
\hline
\end{tabular}


Table 3. The correlation between clinicopathological factors and overall survival (OS) of study Patients

\begin{tabular}{|c|c|c|c|c|c|}
\hline \multirow[t]{2}{*}{ Factors } & \multicolumn{3}{|c|}{ Univariate analysis } & \multicolumn{2}{|c|}{ Multivariate analysis } \\
\hline & $\begin{array}{l}\text { OS } \\
\text { (months) }\end{array}$ & $\mathrm{HR}(95 \% \mathrm{Cl})$ & $P$ & $\mathrm{HR}(95 \% \mathrm{Cl})$ & $P$ value \\
\hline Age $>70 v \leq 70$ ys & $19 \vee 31$ & $1.73(1.22-2.46)$ & 0.002 & $1.35(0.78-2.35)$ & 0.274 \\
\hline Sex Male v Female & 25 v 21 & $0.97(0.69-1.37)$ & 0.881 & & \\
\hline $\mathrm{CCl}>8 \mathrm{v} \leq 8$ & $23 \vee 27$ & $1.28(0.90-1.81)$ & 0.159 & & \\
\hline $\begin{array}{l}\text { Onset with Anemia v } \\
\text { intestinal symptoms }\end{array}$ & $19 \vee 27$ & $1.39(0.83-2.33)$ & 0.199 & & \\
\hline $\begin{array}{l}\text { Cecum } v \text { ascending } v \\
\text { transverse colon cancer }\end{array}$ & $\begin{array}{l}22 v 23 v \\
27\end{array}$ & $1.01(0.89-1.15)$ & 0.824 & & \\
\hline pT 4 v $\leq 3$ & 19 v 40 & $1.82(1.16-2.86)$ & 0.009 & $1.37(0.76-2.44)$ & 0.287 \\
\hline $\mathrm{pN} 2 \vee 1 \vee 0$ & $\begin{array}{l}21 v 41 v \\
43\end{array}$ & $1.34(1.02-1.77)$ & 0.034 & $1.11(0.77-1.59)$ & 0.563 \\
\hline $\begin{array}{l}\text { Mucinous histology YES v } \\
\text { NO }\end{array}$ & $26 \vee 24$ & $0.95(0.65-1.39)$ & 0.823 & & \\
\hline Grading 3-4 v 1-2 & $19 \vee 32$ & $1.65(1.13-2.42)$ & 0.009 & $0.93(0.52-1.65)$ & 0.810 \\
\hline LVI YES v NO & $23 \vee 43$ & $1.84(1.13-2.98)$ & 0.013 & $1.57(0.88-2.82)$ & 0.126 \\
\hline KRAS mut v wt & $23 \vee 26$ & $0.97(0.69-1.37)$ & 0.896 & & \\
\hline NRAS mut $v$ wt & $14 \vee 25$ & $1.62(0.58-4.47)$ & 0.350 & & \\
\hline BRAF mut v wt & 16 v 27 & $1.60(1.06-2.41)$ & 0.020 & $1.97(1.02-3.81)$ & 0.043 \\
\hline MSI-H v MSS & $41 \vee 28$ & $0.60(0.29-1.32)$ & 0.231 & & \\
\hline $\begin{array}{l}\text { Surgery of primary tumor } \\
\text { YES } \vee \text { NO }\end{array}$ & $31 \vee 16$ & $0.38(0.25-0.57)$ & $<0.0001$ & $1.08(0.32-3.65)$ & 0.181 \\
\hline Baseline ECOG PS 1-2 v 0 & $16 \vee 31$ & $2.09(1.4-3.0)$ & $<0.0001$ & $1.74(1.02-2.96)$ & 0.040 \\
\hline $\begin{array}{l}\text { Metachronous v } \\
\text { synchronous metastases }\end{array}$ & $33 \vee 21$ & $0.68(0.47-0.99)$ & 0.045 & $0.72(0.43-1.29)$ & 0.273 \\
\hline $\begin{array}{l}\text { Metastases of peritoneum } \\
\text { v others }\end{array}$ & $20 \vee 26$ & $1.22(1.1-1.46)$ & 0.040 & $1.29(0.96-1.73)$ & 0.084 \\
\hline N. of Metastatic site $\geq 2 \vee 1$ & $21 \vee 31$ & $1.41(0.99-2.01)$ & 0.054 & & \\
\hline $\begin{array}{l}\text { Upfront surgery of liver } \\
\text { metastases Yes v No }\end{array}$ & $43 \vee 20$ & $0.46(0.30-0.71)$ & 0.001 & $0.37(0.20-0.67)$ & 0.001 \\
\hline
\end{tabular}

Abbreviations: CCl: charlson comorbidity index; LVI: lymphovascular invasion; PS: performance status 
Figure 1. a

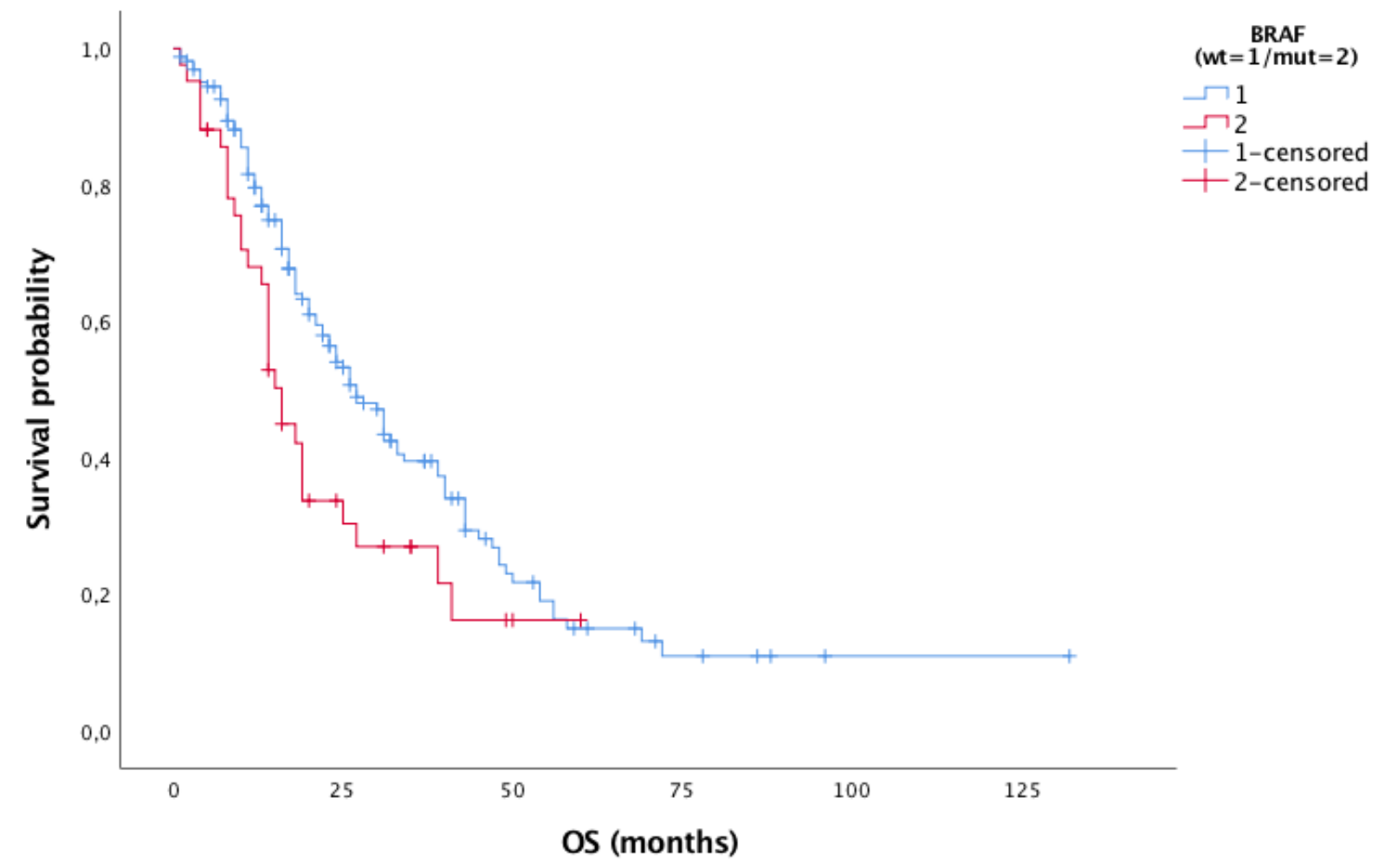

Figure $1 b$

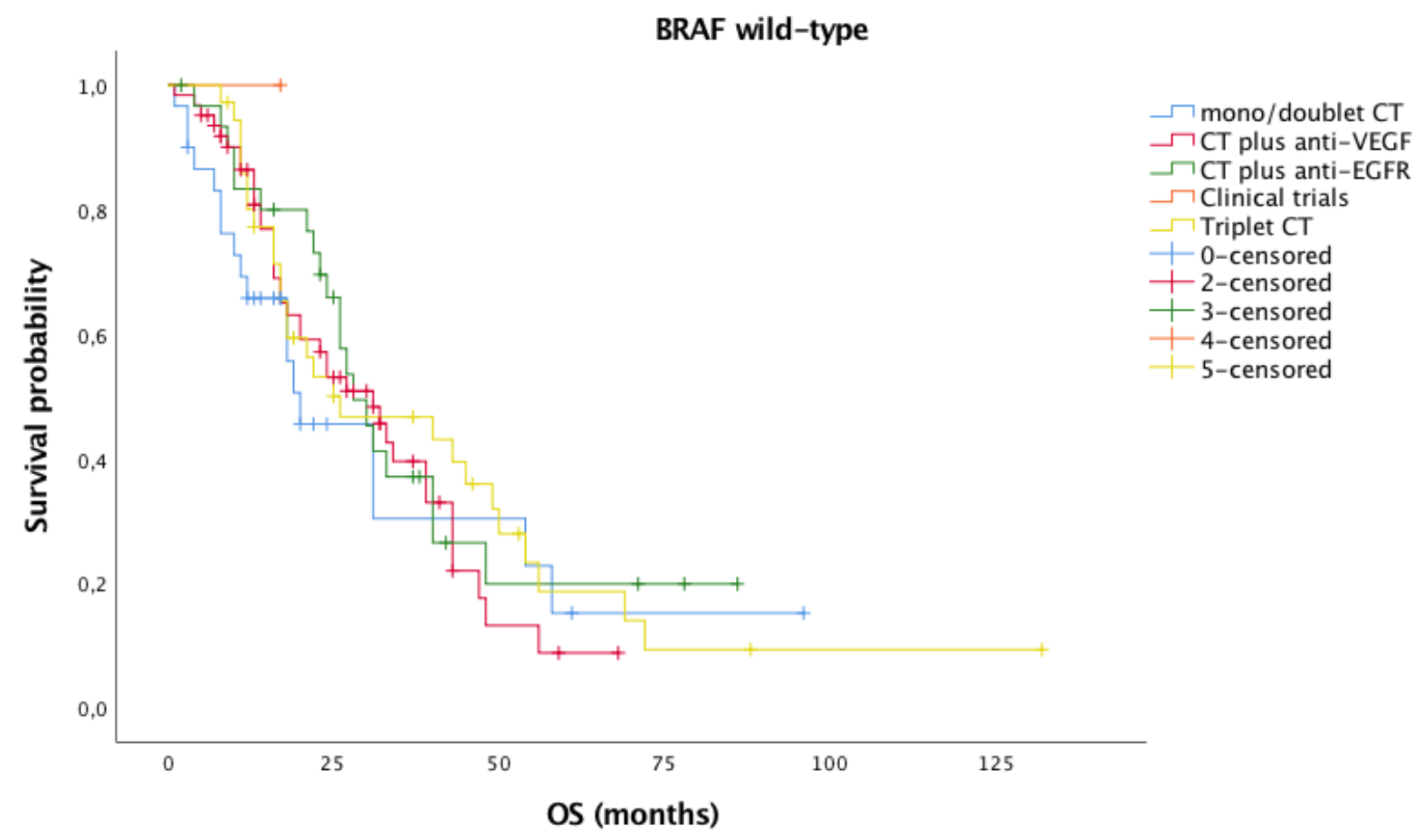


Figure 1c

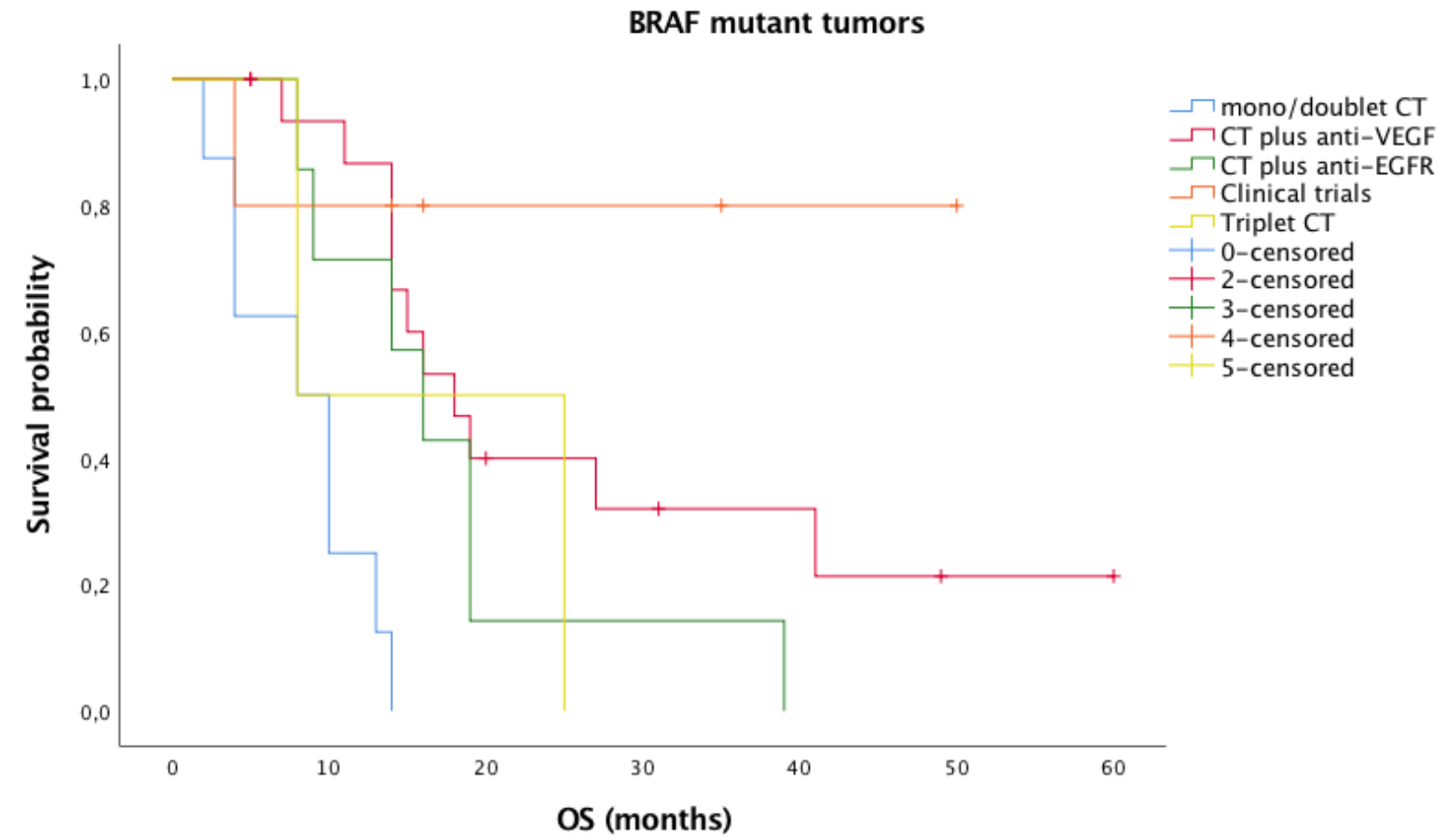


Figure 2. a

Study population Overall Survival (OS)

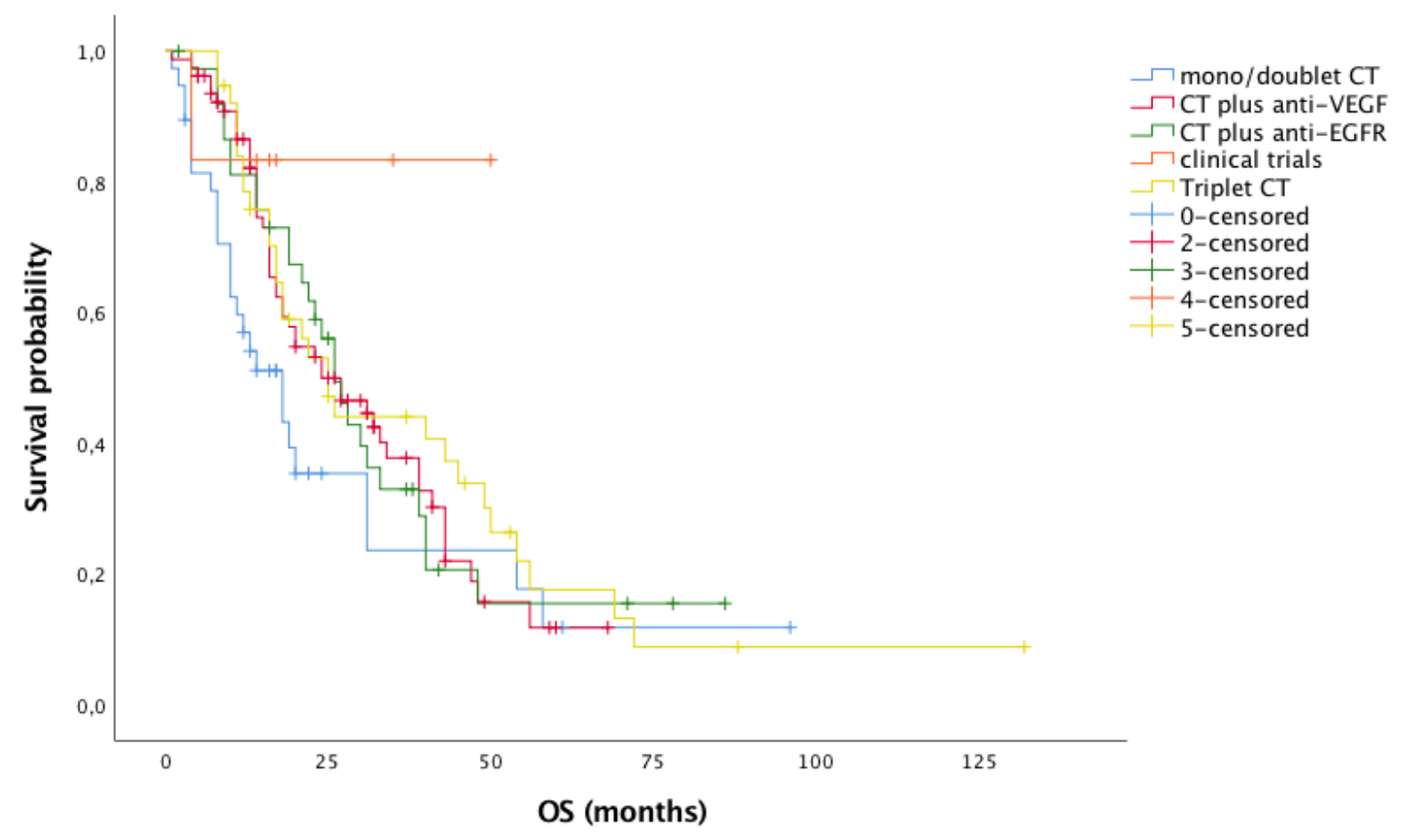

\section{Figure $2 b$}

Progression free sruvival in first line (PFS1) treatment

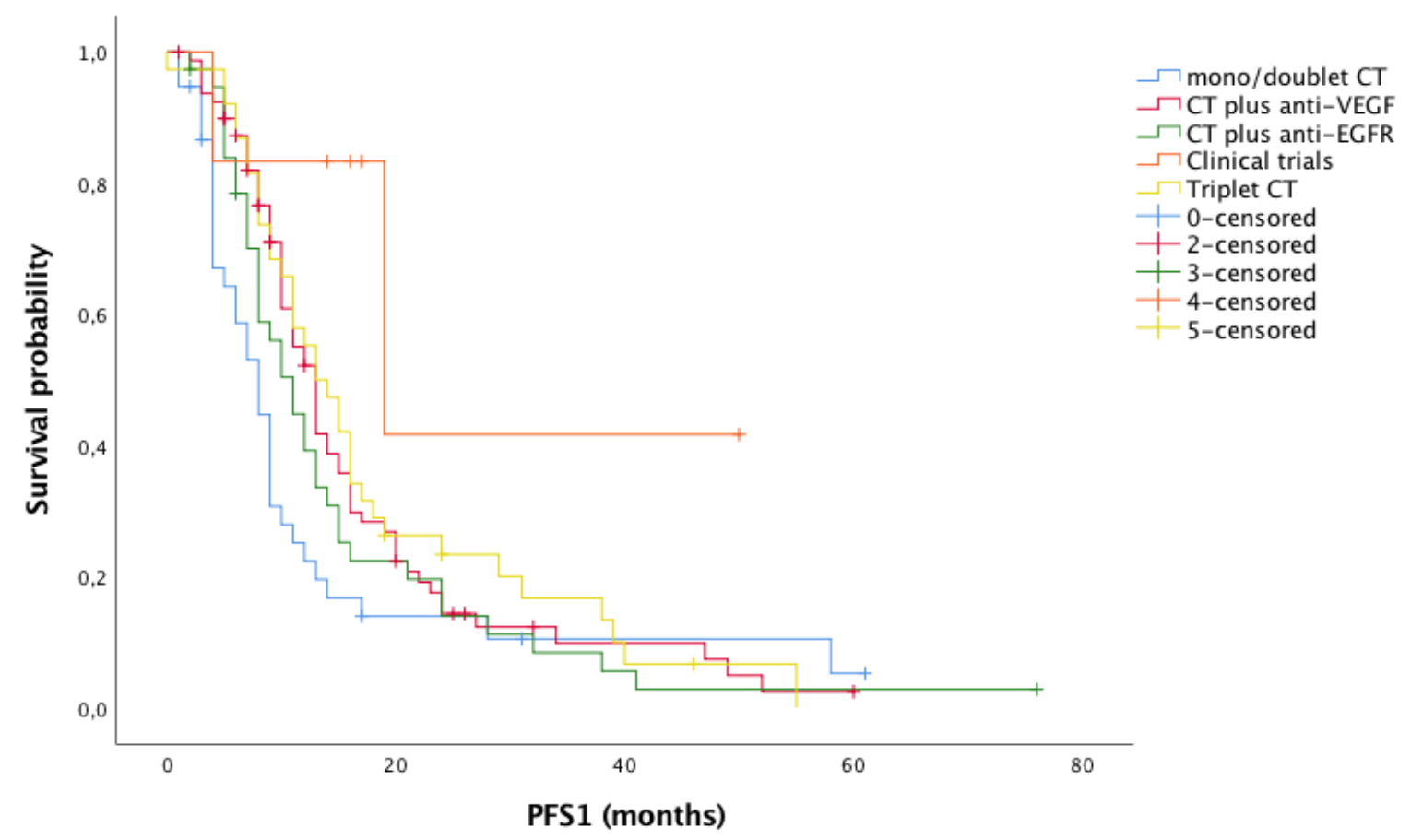


Figure 2c

Progression free survival in second line (PFS2) treatment

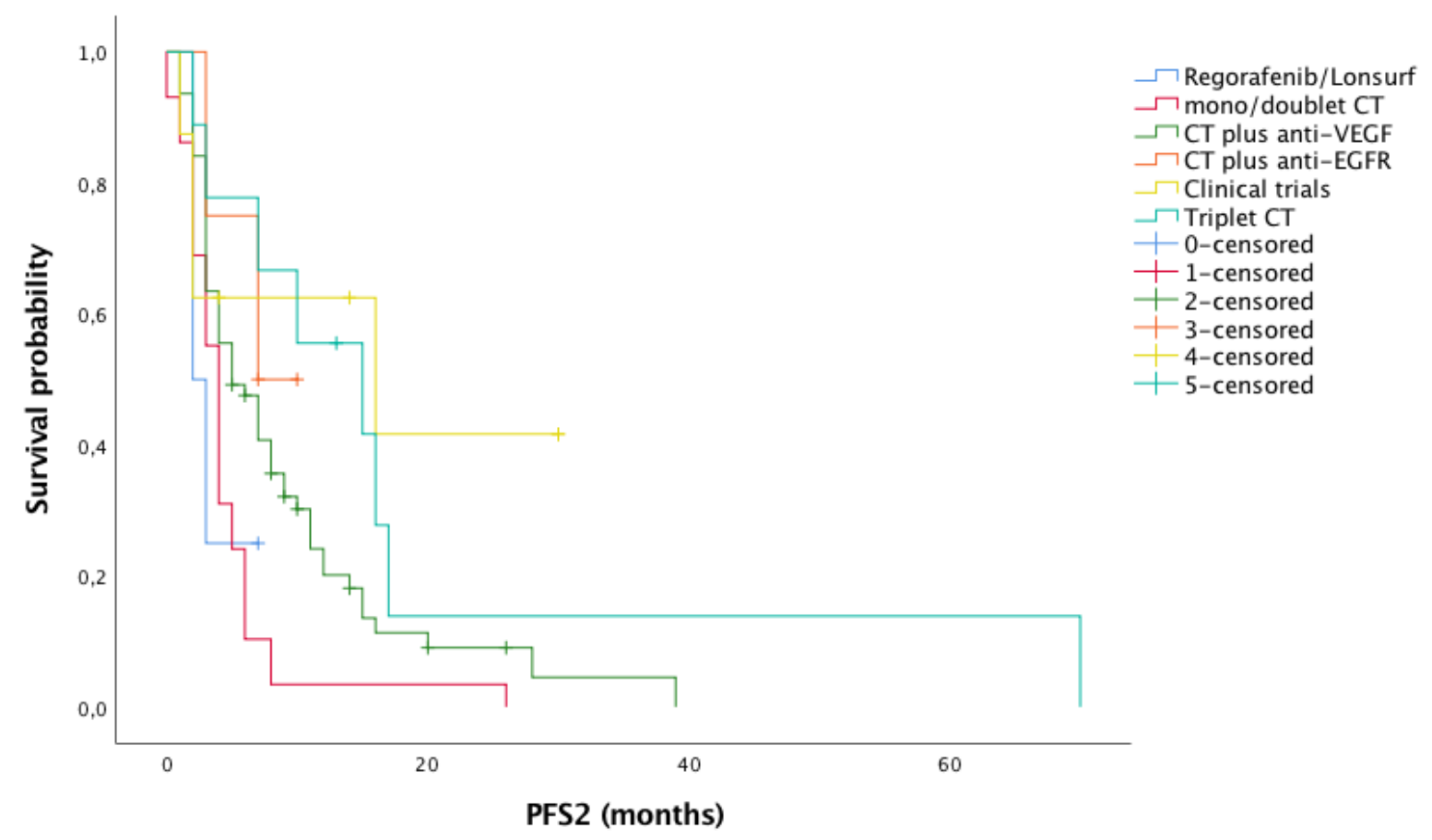

Figure 2d Progression free survival in third line (PFS3) treatment

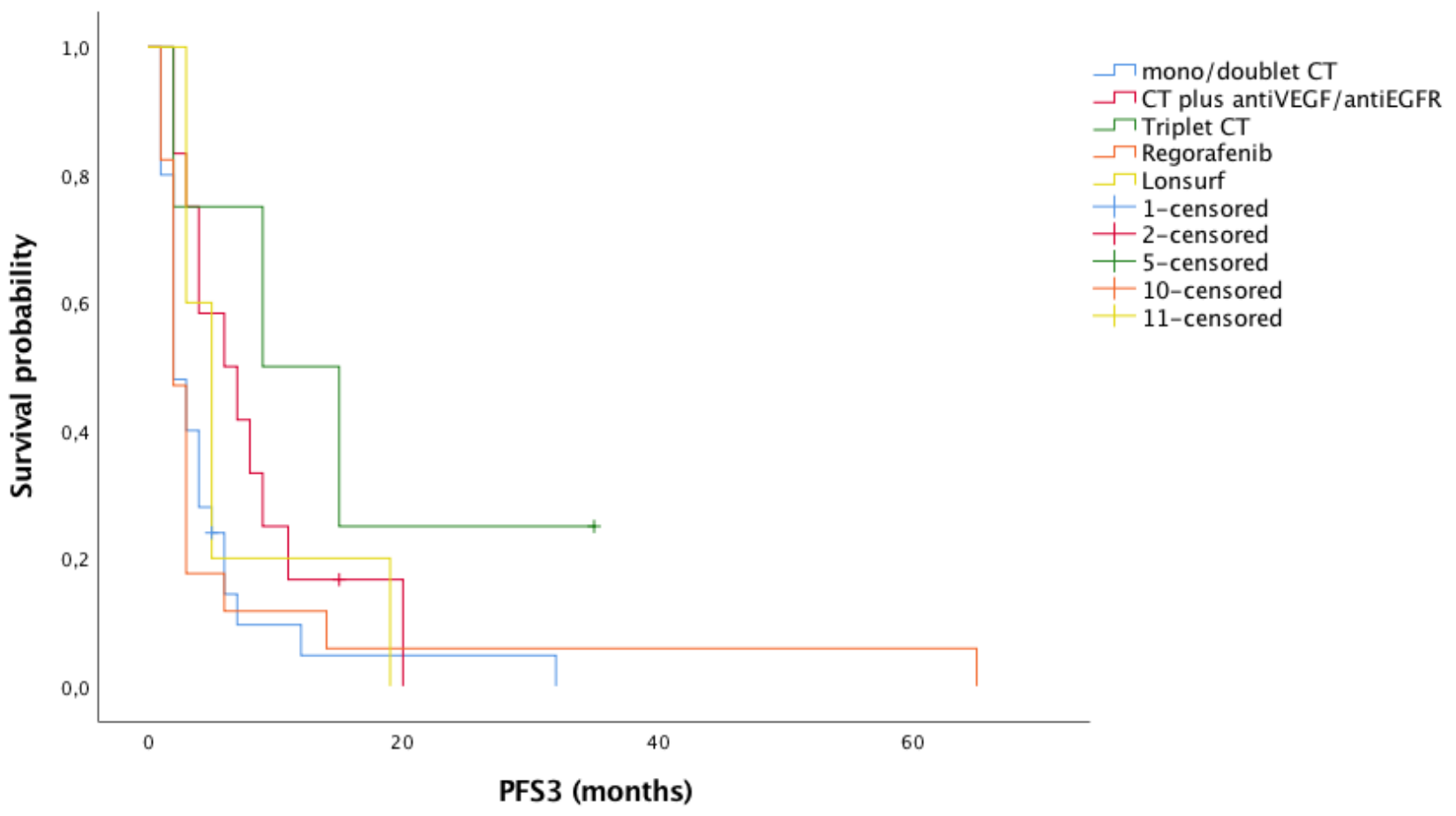


Figure 3. a

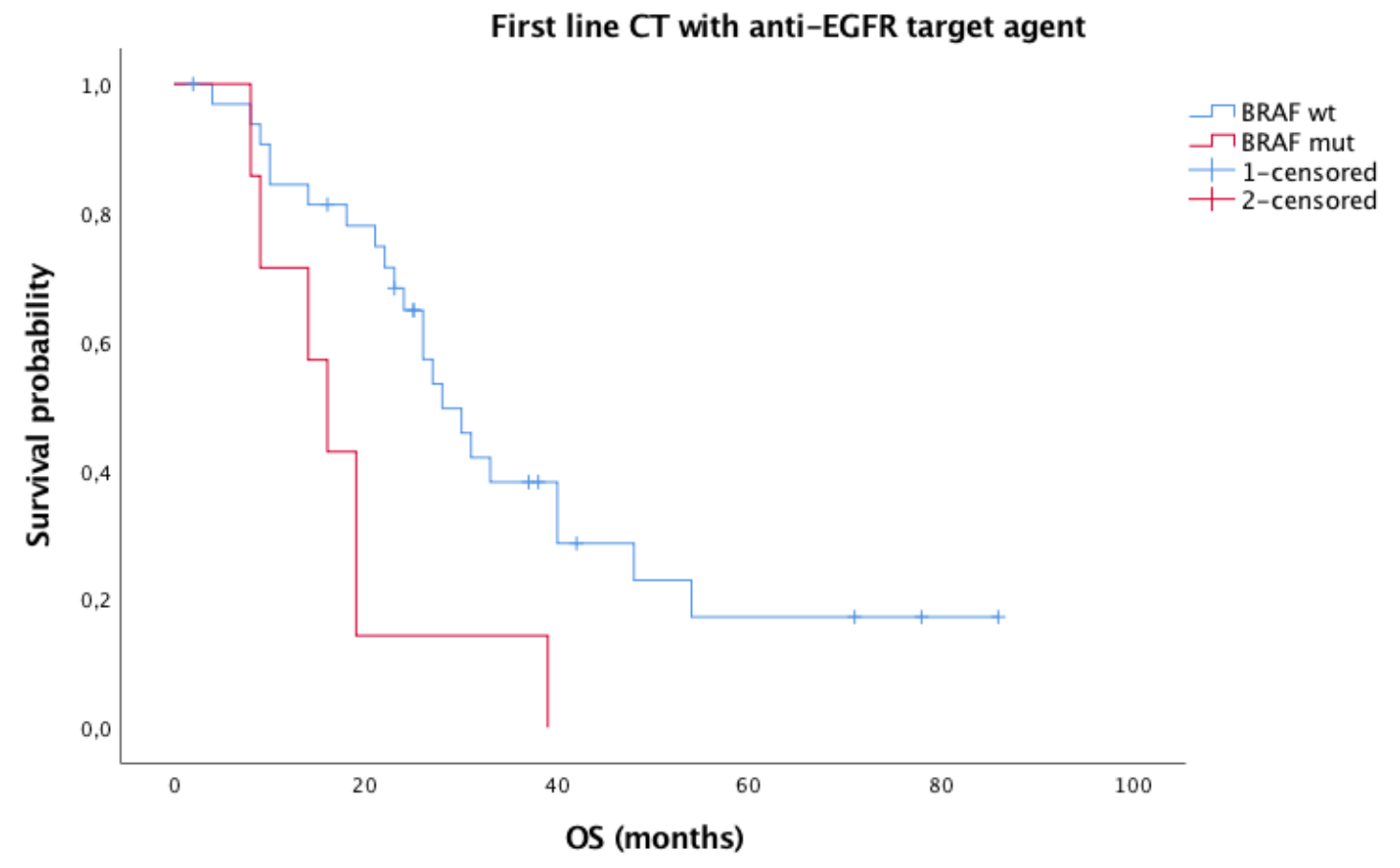

Figure 3b

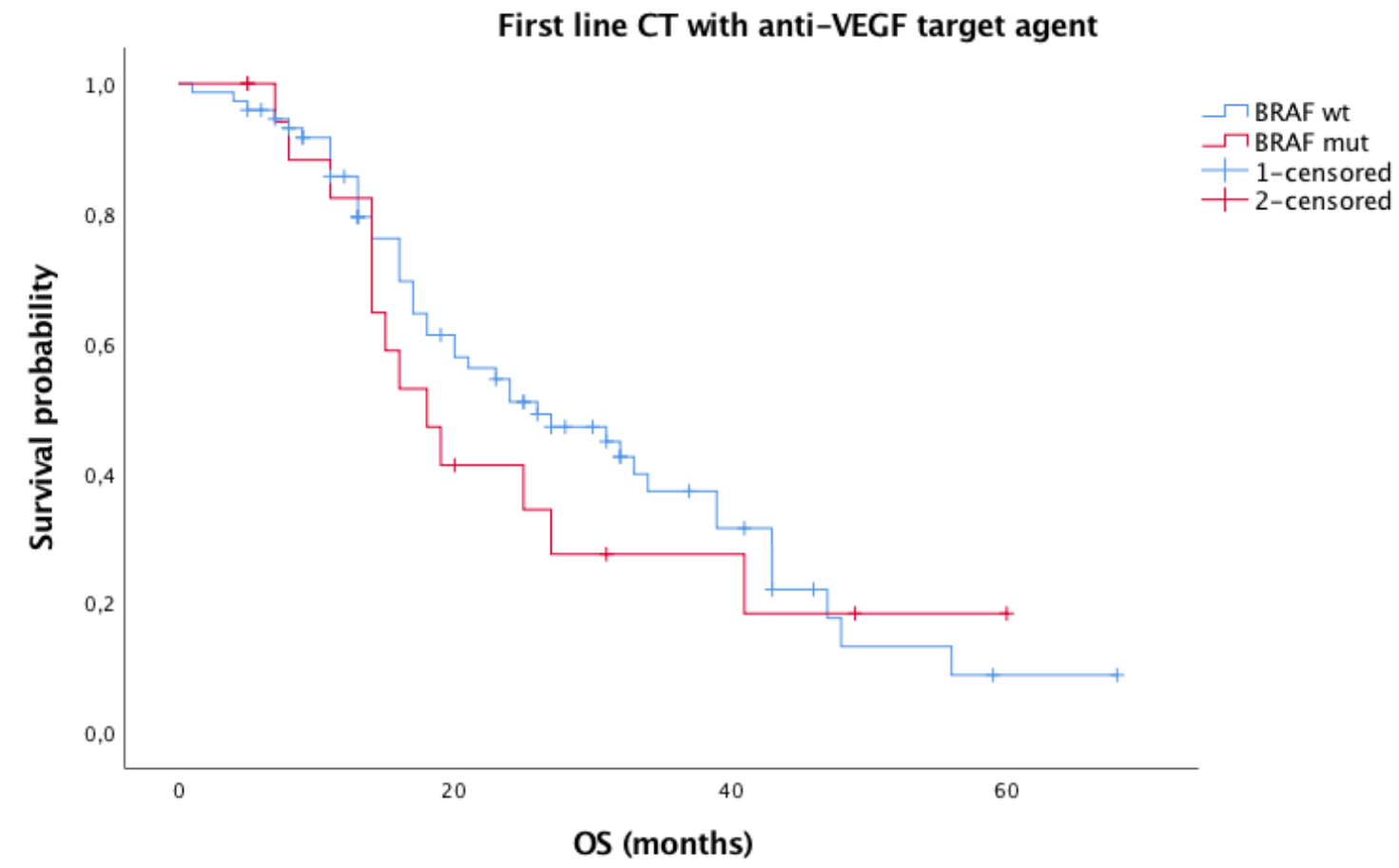

